\title{
ESTUDO DE CASO DO DESEMPENHO DE JUNTAS SOLDADAS PARA APLICAÇÃO OFFSHORE *
}

\author{
Willy Ank de Morais ${ }^{1}$ \\ Adriana Rey Rey ${ }^{2}$ \\ Ethiene Raunaimer Takakura ${ }^{2}$ \\ Felipe de Oliveira Barros ${ }^{3}$ \\ Jeferson Alves de Oliveira ${ }^{3}$ \\ Mauro André Guilherme Vieira Júnior ${ }^{3}$ \\ Wanderley Graça Rivela Júnior ${ }^{3}$ \\ Valmir Demarchi ${ }^{4}$ \\ Nestor Ferreira de Carvalho ${ }^{5}$
}

\section{Resumo}

Este trabalho objetiva a descrição dos diferentes desempenhos sob corrosão de uma junta soldada de uma tubulação de aço carbono obtida pelos consumíveis ER 70S-3 e ER 80S-Ni2, empregada em plataformas offshore. Amostras de tubos e chapas de aço carbono foram soldadas, através do processo TIG, empregando tais consumíveis, e submetidas a ensaio de corrosão acelerada por perda de massa em uma cuba com fluxo constante de água destilada e ácido sulfúrico a $98 \%$. Posteriormente, as amostras foram caracterizadas de modo a quantificar as possíveis alterações nas características mecânicas, estruturais e superficiais. $\mathrm{O}$ resultado final foi que a corrosão ocasionada na junta com o consumível ER 80S-Ni2 apresentou características diferenciadas e mais deletérias ao desempenho estrutural do material, apesar de ser o consumível inicialmente recomendado para a aplicação. Palavras-chave: Corrosão, Perda de Massa, Consumíveis de Soldagem.

\section{CASE STUDY OF PERFORMANCE OF WELDED JOINTS FOR OFFSHORE APPLICATIONS}

\section{Abstract}

This work has as objective to describe the different performances under corrosion of a welded joint composed of a carbon steel pipe obtained with ER 70S-3 and ER 80S$\mathrm{Ni} 2$ consumables and used at offshore platforms. Samples of carbon steel tubes and plates were welded through TIG process, using the different consumables, and were subjected to accelerated corrosion test by mass loss in a tank with constant flow of distilled water and $98 \%$ sulfuric acid. Subsequently, the samples were characterized in order to identify possible changes in the mechanical, structural and surface characteristics. As the result corrosion caused in the joint with the ER 80S-Ni2 consumable showed more deleterious to the structural performance of the material, despite being the consumable initially recommended for the application.

Keywords: Corrosion, Mass Loss, Welding Consumable.

1 Doutorando, Mestre, Engenheiro e Técnico em Metalurgia e Materiais, Sócio-Diretor da Willy Ank Soluções Metal-Mecânicas, Professor Mestre da UNAERP-Guarujá e Professor Adjunto da Universidade Santa Cecília (UNISANTA), Santos, SP, Brasil (willyank@unisanta.br).

2 Graduandas em Engenharia Mecânica UNISANTA, Santos, SP, Brasil (arrey@uol.com.br).

3 Graduandos em Engenharia Mecânica UNISANTA, Santos, SP, Brasil (mjunior001@icloud.com).

4 Mestre, Engenheiro Mecânico. Professor da UNISANTA e TP/PBE (D/AM) - Engenharia Mecânica Motores Médios da Mercedes-Benz do Brasil Ltda., São Bernardo do Campo, SP, Brasil (valmir.demarchi@daimler.com).

5 Mestre em Engenharia Mecânica, Engenheiro Químico. Professor da Universidade Santa Cecília (UNISANTA), Santos, SP, Brasil (nestor.fcar@gmail.com). 


\section{INTRODUÇÃO}

Tubulações, fabricadas a partir de juntas soldadas, são muito utilizadas para escoar de forma correta os produtos produzidos nas indústrias de modo geral. Esses equipamentos podem ser encontrados em diversos ambientes, inclusive marítimos, sofrendo a influência de diversos processos, como exemplo, a corrosão e temperaturas de aplicação que afetam diretamente as propriedades físicas e mecânicas dos materiais metálicos utilizados.

Há muitos anos a humanidade sofre com o problema da corrosão e procura formas de prevenção, por isso é muito importante o estudo completo do material que será aplicado, do processo onde será utilizado e do ambiente em que se encontra. Um dos motivos principais de se buscar a correta aplicação e métodos preventivos da corrosão é o custo; atualmente gastam-se bilhões de dólares devido às perdas por corrosão, os quais poderiam ser evitados com um estudo aprimorado deste processo [1].

O presente trabalho teve como base um estudo realizado anteriormente, análise do desempenho de uma junta soldada para tubulações de uma plataforma marítima [2], que foi realizado após a solicitação de uma empresa contratada para realizar serviços de soldagem em tubulações de aço carbono ASTM A333 Gr.6 com condições de trabalho para baixa temperatura, $0^{\circ} \mathrm{C}$ com picos de até $-20^{\circ} \mathrm{C}$, no segmento offshore com aplicação de consumíveis, o ER 80S-Ni2, porém com custo elevado. A contratada solicitou um estudo para viabilizar a utilização de um consumível comum, ER 70S-3, realizado através de análise química e mecânica do aço e dos consumíveis em questão. E após soldagem com ER $70 S-3$ foi realizado ensaio de impacto Charpy.

Apesar do consumível ER 80S-Ni2 ser especificado para uso em baixas temperaturas, este possui uma composição química e características técnicas que não recomendariam o seu emprego na tubulação estudada, que é empregada em uma plataforma offshore [2].

Visando dar continuidade no estudo feito anteriormente, será realizado um estudo de compatibilidade mecânica, através de ensaio de tração, química e do ensaio de perda de massa por corrosão acelerada, em chapas e tubos de aço carbono estrutural comum, soldados com consumíveis similares e dissimilares, ER 70S-3 e ER 80S-Ni2, para aplicação em tubulação de baixa temperatura no segmento offshore a fim de quantificar, através dos dados obtidos durante um determinado tempo o processo de corrosão decorrente da aplicação destes consumíveis no processo de soldagem e também análise superficiais de rugosidade.

Para este estudo foram realizadas pesquisas referentes a normas aplicáveis, processos de soldagem, tipos de corrosão e ensaios para determinação dos valores a serem quantificados durante o experimento a ser realizado.

\section{MATERIAIS E MÉTODOS}

O presente estudo foi desenvolvido empregando várias técnicas experimentais. Basicamente, foram fabricadas juntas soldadas de aço carbono, na forma de chapas e tubos, com consumíveis de aço carbono (ER 70S-3) e de aço ligado ao Níquel (ER $80 \mathrm{SNi2}$ ), que foram submetidas a ensaios de corrosão acelerada e posteriormente caracterizadas.

Para a realização da soldagem e dos ensaios de corrosão e caracterização foram utilizados os seguintes materiais: 
- Tubo de aço carbono SAE J403 1020, diâmetro de 4" nominal (114,3 mm) e espessura de 7,9 $\mathrm{mm}$.

- $\quad$ Chapa de aço carbono ASTM A36 com espessura de 5,0 mm.

- $\quad$ Consumível de soldagem, vareta para processo TIG (GTAW), ER80S-Ni2 com diâmetro de 2,4 mm.

- $\quad$ Consumível de soldagem, vareta para processo TIG (GTAW), ER70S-3 com diâmetro de 3,2 $\mathrm{mm}$.

- $\quad$ Água destilada $\left(\mathrm{H}_{2} \mathrm{O}\right)$

- $\quad$ Ácido sulfúrico

Os equipamentos utilizados na soldagem e nos ensaios de corrosão e caracterização foram seguintes:

- $\quad$ Conjunto de cubas acrílica com capacidade total de 60 litros;

- $\quad$ pHmetro Ajmcronal AJX-512;

- $\quad$ Máquina de solda Miller CST-280;

- $\quad$ Máquina de serra fita industrial Franho FM 1600;.

- Equipamento de preparação metalográfica (prensa de embutimento, lixadoras, politriz);

- $\quad$ Microscópio Oplympus Modelo BX60M;

- $\quad$ Máquina universal de ensaios mecânicos EMIC modelo DL10.000;

- $\quad$ Rugosímetro Mitutoyo SJ-201.

- $\quad$ Balança digital Marte modelo AL500.

\subsection{Confecção dos Corpos de Prova (CPs)}

A confecção das amostras foi realizada nas instalações do Centro de SoldagemINSPEBRAS $^{\circledR}$, iniciado através da soldagem do tubo e da chapa, utilizando o processo TIG (GTAW) e seguindo os parâmetros da Especificação de Procedimento de Soldagem. Os parâmetros de soldagem aplicados durante o processo e o cálculo do aporte térmico são demonstrados na Tabela 1.

Tabela 1. Parâmetros de soldagem utilizados e cálculo do aporte de energia.

\begin{tabular}{c|c|c|c|c|c|c|c|c|c}
\hline \multirow{2}{*}{ Processo } & \multicolumn{3}{|c|}{ Consumível } & \multicolumn{3}{|c|}{ Corrente Elétrica } & Tensão \\
\cline { 2 - 10 } & Espec. & Classif. & $\begin{array}{c}\text { Diam. } \\
(\mathbf{m m})\end{array}$ & Tipo & Polaridade & $\begin{array}{c}\text { Amperes } \\
\text { (A) }\end{array}$ & $\begin{array}{c}\text { Aporte de } \\
(\mathbf{m m} / \mathbf{m i n})\end{array}$ & $\begin{array}{c}\text { Energia } \\
\text { (kJ) }\end{array}$ \\
\hline GTAW & 5.18 & ER 70S-3 & 3,2 & CC & $(-)$ & 110 & 12 & 59 & $\mathbf{1 , 3 4}$ \\
\hline GTAW & 5.28 & ER 80S-Ni2 & 2,5 & CC & $(-)$ & 120 & 11 & 65 & $\mathbf{1 , 2 2}$ \\
\hline
\end{tabular}

Foram confeccionadas, utilizando máquina de solda Miller CST-280, 04 (quatro) amostras, sendo 2 chapas e 2 tubos, fabricados com o consumível ER 70S-3 conforme EPS criada pelos autores, com assessoria da INPEBRAS e 2 tubos, fabricados com o consumível ER 80S-Ni2, também em obediência a uma EPS criada especialmente para este fim.

Após a soldagem, foram retirados 6 corpos de prova de cada amostra totalizando 24 CPs, apresentados na Figura 1. O corte foi executado utilizando máquina de serra fita refrigerada FM 1600, fabricada pela Franho, com dimensões apresentadas na Figura 2. Os CPs obtidos, identificados numericamente por pulsão, foram analisados através dos ensaios conforme Tabela 2. 


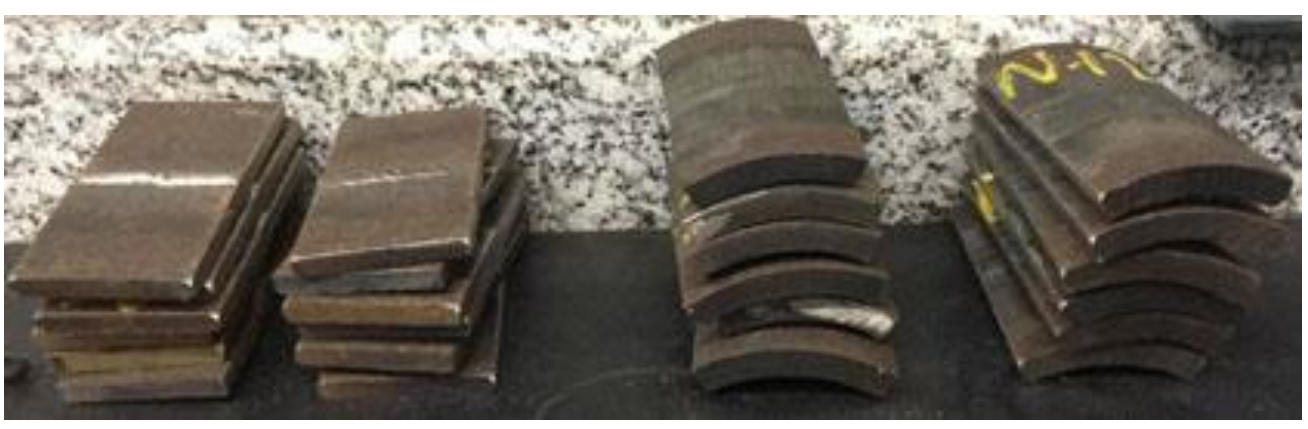

Figura 1. Corpos de prova confeccionados preparados para este trabalho.
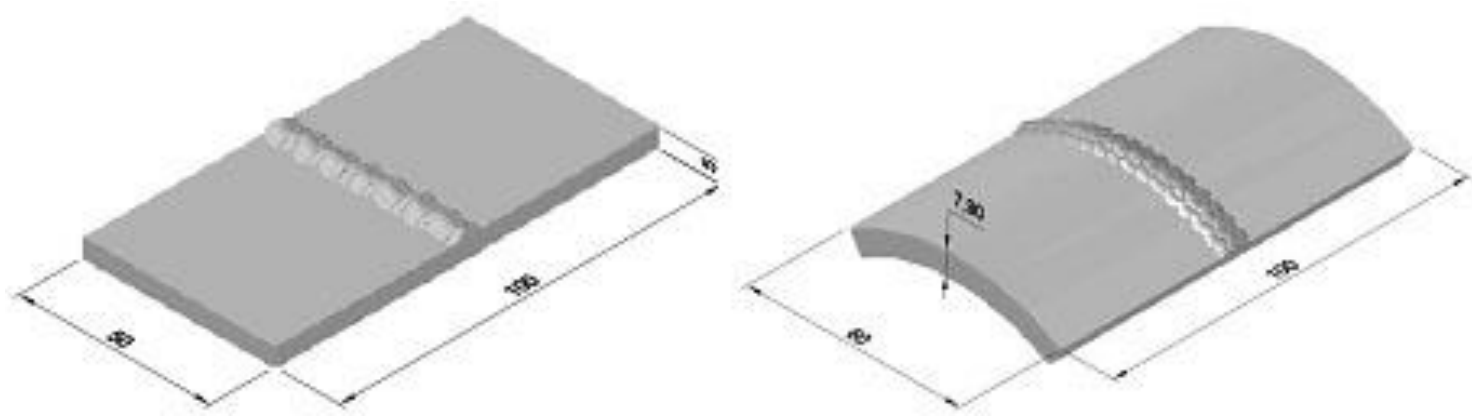

Figura 2. Dimensões do Corpos de prova após o corte oriundo: esquerda da chapa; direita do tubo.

Tabela 2. Definição dos Ensaios por Corpo de Prova.

PROGRAMAÇAOO DE EISAIOS

\begin{tabular}{|c|c|c|c|c|c|c|}
\hline COWSUMIVEL & $\begin{array}{l}\text { TUBO_1 } \\
\text { CHAPA_1 }\end{array}$ & $\begin{array}{l}\text { TUBO_2 } \\
\text { CHAPA_2 }\end{array}$ & $\begin{array}{l}\text { TUBO_3 }^{3} \\
\text { CHAPA_ } 3\end{array}$ & $\begin{array}{l}\text { TUBO_4 } \\
\text { CHAPA_4 }\end{array}$ & $\begin{array}{l}\text { TUBO_5 } \\
\text { CHAPA_5 }\end{array}$ & $\begin{array}{l}\text { TUBO_6 } 6 \\
\text { CHAPA_6 }\end{array}$ \\
\hline \multicolumn{7}{|c|}{$1^{\circ} E T A P A$} \\
\hline ERTOS-3 & $\begin{array}{l}\text { DUREZA } \\
\text { TRAÇẤO }\end{array}$ & $\begin{array}{l}\text { DUREZA } \\
\text { TRAÇÃ̂́ }\end{array}$ & $\begin{array}{l}\text { MACROGRAFIA } \\
\text { MICROGRAFIA }\end{array}$ & $\begin{array}{l}\text { PERDA DE MASSA } \\
\text { RUGOSIDADE }\end{array}$ & $\begin{array}{c}\text { PERDA DE MASSA } \\
\text { RUGOSIDADE }\end{array}$ & $\begin{array}{l}\text { PERDA DE MASSA } \\
\text { RUGOSIDADE }\end{array}$ \\
\hline ER80S-Ni2 & $\begin{array}{l}\text { DUREZA } \\
\text { TRAÇẤO }\end{array}$ & $\begin{array}{l}\text { DUREZA } \\
\text { TRAÇÃ̈O }\end{array}$ & $\begin{array}{l}\text { MACROGRAFIA } \\
\text { MICROGRAFIA }\end{array}$ & $\begin{array}{l}\text { PERDA DE MASSA } \\
\text { RUGOSIDADE }\end{array}$ & $\begin{array}{c}\text { PERDA DE MASSA } \\
\text { RUGOSIDADE }\end{array}$ & $\begin{array}{l}\text { PERDA DE MASSA } \\
\text { RUGOSIDADE }\end{array}$ \\
\hline & & & & \multicolumn{3}{|c|}{ Ensaio de Corrosão } \\
\hline \multicolumn{7}{|c|}{$2^{\circ} E T A P A$} \\
\hline ER7OS-3 & & & & $\begin{array}{l}\text { PERDA DE MASSA } \\
\text { RUGOSIDADE } \\
\text { DUREZA } \\
\text { TRAÇÄAO }\end{array}$ & $\begin{array}{l}\text { PERDA DE MASSA } \\
\text { RUGOSIDADE } \\
\text { DUREZA } \\
\text { TRAÇÄO }\end{array}$ & $\begin{array}{l}\text { PERDA DE MASSA } \\
\text { RUGOSIDADE }\end{array}$ \\
\hline ER80S-Ni2 & & & & $\begin{array}{l}\text { PERDA DE MASSA } \\
\text { RUGOSIDADE } \\
\text { DUREZA } \\
\text { TRAÇĀAO }\end{array}$ & $\begin{array}{l}\text { PERDA DEMASSA } \\
\text { RUGOSIDADE } \\
\text { DUREZA } \\
\text { TRAÇÄA }\end{array}$ & $\begin{array}{l}\text { PERDA DE MASSA } \\
\text { RUGOSIDADE }\end{array}$ \\
\hline
\end{tabular}

\subsection{Ensaio de Corrosão Acelerada por Perda de Massa}

Foi utilizado o processo de corrosão acelerada para obter resultados com maior rapidez e para estudar o comportamento da corrosão controlando os parâmetros, temperatura, $\mathrm{pH}$ e concentração. Para a iniciação deste processo, os CPs sofreram uma limpeza mecânica manual com a utilização de escova de aço rotativa, e em 
seguida uma limpeza com acetona para remover impurezas, podendo ser visto na Figura 3, para em seguida serem posicionados na cuba.
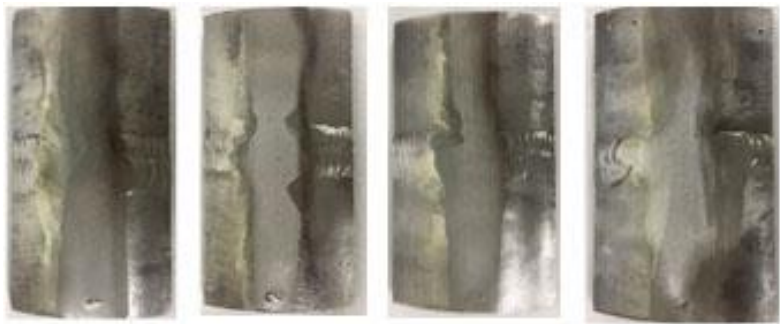

a) Tubo
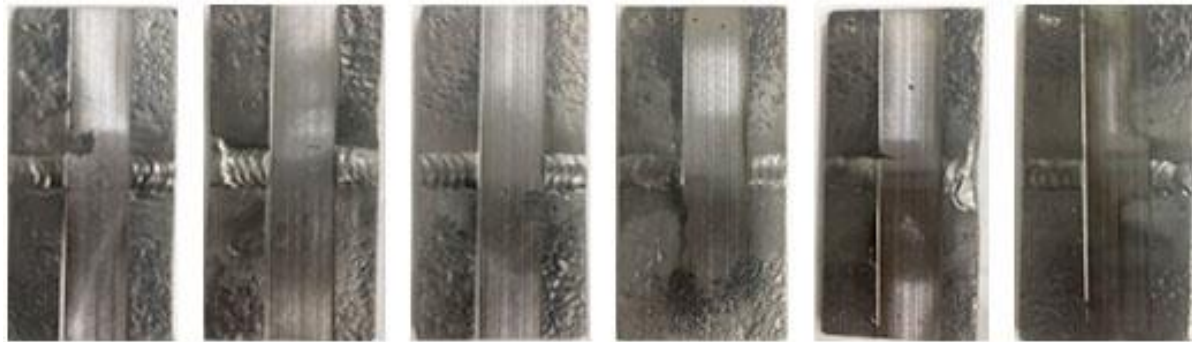

b) Chapa
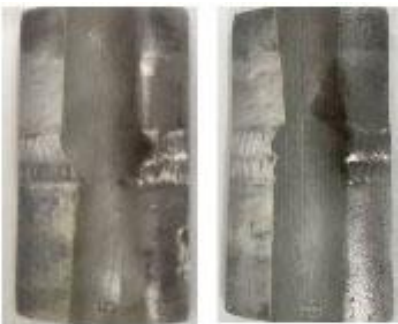

Figura 3. CPs de chapas e tubos preparados antes da inserção na cuba. A linha de retificação central foi necessária para homogeneizar a superfície para a medição da rugosidade.

A cuba utilizada para realização do ensaio, presente no laboratório de operações unitárias da UNISANTA - Universidade Santa Cecília, tem dimensões conforme Figura 4, com capacidade volumétrica máxima de 60 litros garantindo imersão total dos CPs e possuindo uma circulação constante, que garante uma velocidade entre 0,5 e $2 \mathrm{~m} / \mathrm{s}$, para minimizar a possibilidade de erosão e de deposição.
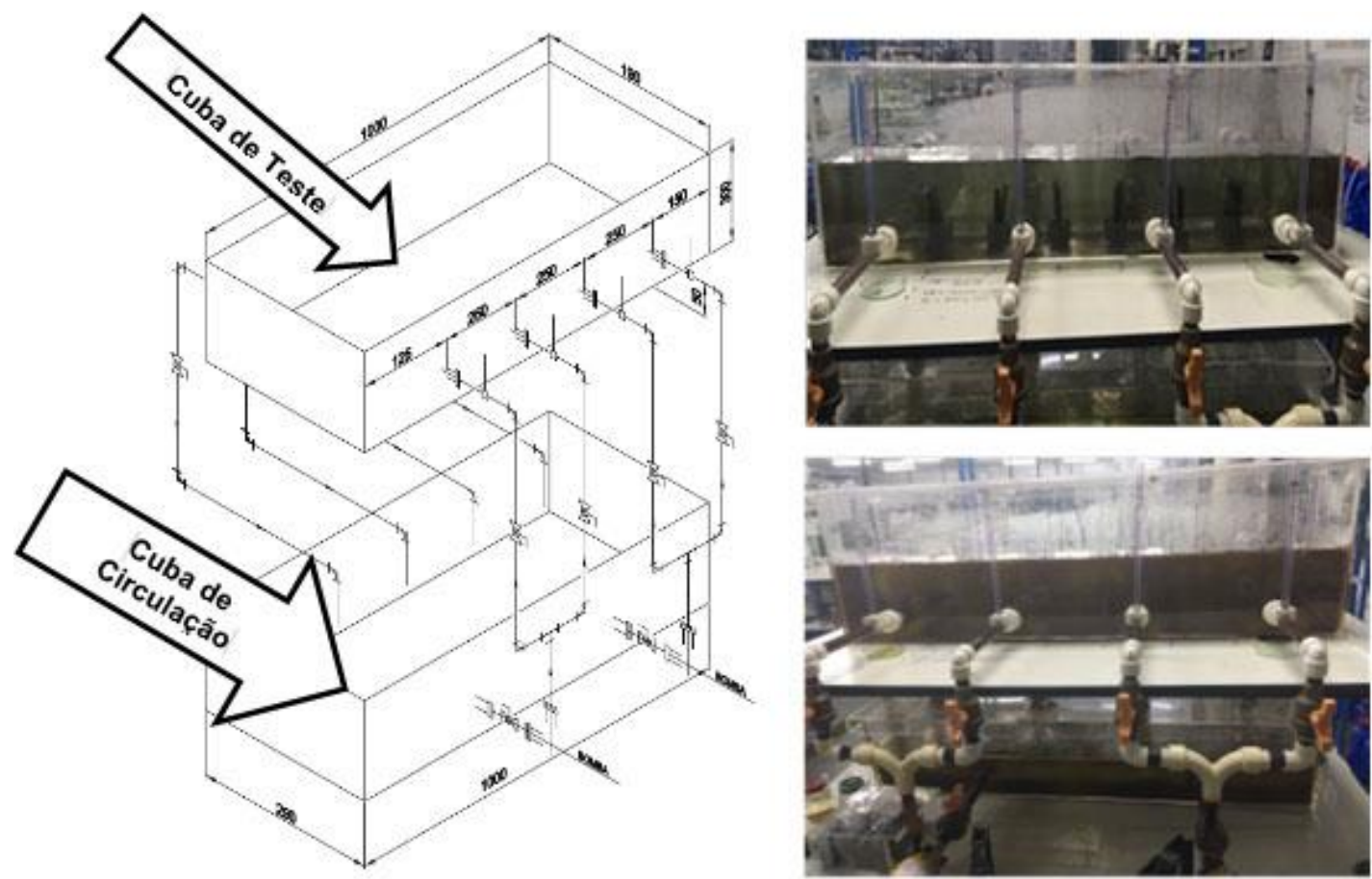

Figura 4. Cuba para ensaio de corrosão: esquema dimensional (esquerda) e foto em uso (direita). 
Os testes de corrosão foram realizados por imersão das amostras em uma solução aquosa de ácido sulfúrico na concentração de 0,25 molar. Durante todo o ensaio o $\mathrm{pH}$ da solução foi inferior a 3,5 o que não levou à necessidade da reposição de ácido. A duração do teste foi definida em 17 dias, tendo como base os experimentos desenvolvidos por Carvalho [3]. Durante o ensaio foi realizado em acompanhamento diário do $\mathrm{pH}$ e temperatura da solução, com exceção dos domingos e feriados, totalizando 14 medições.

Antes da imersão dos CPs na cuba foi realizada uma pesagem individual, utilizando uma balança digital Marte modelo AL500 com precisão de 0,01 g, para realizar a comparação com a massa final e assim tornar possível o cálculo da taxa de corrosão por perda de massa.

\subsection{Ensaios de Caracterização}

Neste trabalho foram empregados ensaios de análise estrutural, superficial e de propriedades mecânicas para caracterizar as amostras antes e após os ensaios de corrosão acelerada.

\subsubsection{Análise Estrutural}

Neste estudo, ensaios metalográficos, que são empregados para correlacionar as propriedades físicas do material com a sua estrutura, foram realizados macrograficamente e micrograficamente.

- Macrografia - foram preparados os 4 CPs reservados a esta análise, conforme Tabela 2, através de lixamento fino e ataque químico. Para a realização do ataque químico, foi utilizado uma aplicação de reagente de Nital 3\% (3ml de Ácido Nítrico concentrado $\left(\mathrm{HNO}_{3}\right)$ e $97 \mathrm{ml}$ de álcool etílico (P.A), após rápida reação, efetuou-se uma lavagem com água corrente, álcool etílico e uma aplicação de jato de ar quente.

- Micrografia - os 4 CPs analisados macrograficamente foram posteriormente polidos com diamante em suspensão de $6 \mu \mathrm{m}$, seguida de uma lavagem com água corrente, álcool etílico e uma aplicação de jato de ar quente.

O ensaio micrográfico foi realizado utilizando microscópio Oplympus Modelo BX60M para gerar imagens das regiões do metal de solda, metal base e zona termicamente afetada com magnificações superiores a 50X.

\subsubsection{Rugosidade}

Com intuito de obter parâmetros iniciais de rugosidade foi necessário realizar uma preparação de superfície regular, através do processo de retificação inserindo uma pista de medição, transversal ao cordão de solda visível na Figura 3, e com isto obter um padrão para comparação da evolução da rugosidade nos CPs. A medição de rugosidade, realizado no laboratório de metalografia da UNISANTA utilizou um rugosímetro portátil digital, Mitutoyo SJ-201, que forneceu a leitura dos pontos de rugosidade $\mathrm{Ra}$ e $\mathrm{Ry}$, em três regiões distintas: metal base (MB), zona termicamente afetada (ZTA) e metal de solda (MS) dos CPs.

$O$ rugosímetro foi posicionado de maneira que sua agulha (apalpador) percorresse um caminho perpendicular ao sentido de retificação da pista existente no respectivo 
$\mathrm{CP}$, criando sulcos com direções definidas, para evitar medições incorretas ao acabamento superficial a ser analisado. As medições foram feitas antes e após os ensaios de corrosão acelerada

\subsubsection{Ensaios Mecânicos}

Para análise do ensaio de tração se fez necessário adequar os CPs pré-fabricados, usinando-os a fim de reduzir a espessura para inferior a $5 \mathrm{~mm}$, dimensão admissível pela garra da máquina de tração. Foi preservado, no processo de usinagem o acabamento na face do cordão da solda nos CPs, antes e após o processo de corrosão acelerada.

Devido as dimensões necessárias para a imersão dos mesmos na cuba de corrosão, não se adotou dimensões normalizadas e para não reduzir a área contendo produtos de corrosão, foi mantido a sua forma retangular. Este formato, mantendo as dimensões requisitadas pela cuba do ensaio de corrosão acelerada, estão conforme a NBR 8164:1983. Esta norma foi concebida para avaliar as características plásticas de metais e não prevê a redução de seção reta do CP empregado, pois o ensaio é considerado apenas até o início da estrição. Um CP deste tipo tende a apresentar estricção fora da região central, provavelmente no ponto de contato com as garras da máquina, no qual as tensões possuem uma ligeira concentração de tensão. As dimensões médias dos CPs foram definidas conforme mostrado na Figura 5

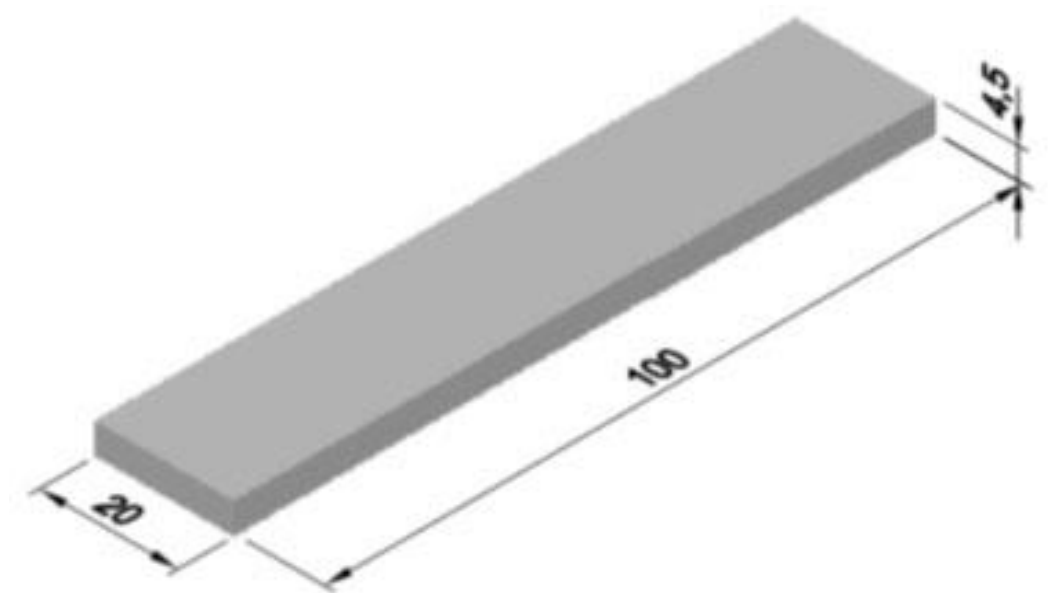

Figura 5. Dimensões médias dos CPs para ensaios de tração.

A fim de avaliar a influência da corrosão superficial no comportamento mecânico das juntas soldadas, foi realizado ensaio de tração para os CP's designados conforme Tabela 2, para a $1^{\text {a }}$ e $2^{\underline{a}}$ etapa (antes e após os ensaios de corrosão acelerada). Em todas as amostras foi empregada a velocidade de deformação de $10 \mathrm{~mm} / \mathrm{min}$ e os mesmos parâmetros de configuração da máquina. Como o objetivo foi apenas comparar os resultados, não houve a necessidade de determinar o coeficiente de elasticidade característico do material, com a utilização de extensômetro, sendo suficiente a curva registrada diretamente pela máquina de tração, sem extensômetro.

\section{RESULTADOS E DISCUSSÃO}

Foi realizada análise química, em duas amostras, chapa e tubo, antes da confecção dos CPs. A Tabela 3 confirma que a composição química está de acordo com a 
desejada para o material base aplicado no estudo em comparação a Norma ASTM A333 Gr. 6 [2].

Tabela 3. Resultados da análise química da chapa e do tubo empregados neste trabalho.

\begin{tabular}{|c|c|c|c|c|c|}
\hline & $\mathrm{Ch}$ & $\mathrm{pa}$ & & & \\
\hline & Cha & & & Tut & \\
\hline & Nitrogenio & 0,0085 & & Nitrogenio & 0,0028 \\
\hline & Alumínio & 0,0270 & & Alumínio & 0,0260 \\
\hline & Boro & $<0,0003$ & & Boro & $<0,0003$ \\
\hline 总 & Carbono & 0,1700 & \& & Carbono & 0,2100 \\
\hline$\frac{\Omega}{\varepsilon}$ & Cromo & 0,0300 & ${ }^{2}$ & Cromo & 0,0400 \\
\hline$\Phi$ & Cobre & 0,0400 & $\Phi$ & Cobre & $<0,002$ \\
\hline 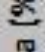 & Manganês & 0,8200 & s & Manganês & 0,5300 \\
\hline$\stackrel{0}{\exists}$ & Molibdênio & $<0,004$ & $\cong$ & Molibdênio & 0,0100 \\
\hline$\Phi$ & Niobio & $<0,002$ & $\$$ & Niobio & $<0,002$ \\
\hline 운 & Níquel & 0,0200 & 운 & Níquel & 0,0100 \\
\hline$\Phi$ & Fósforo & 0,0140 & $\Phi$ & Fósforo & 0,0150 \\
\hline$\Phi$ & Enxofre & 0,0110 & $\Phi$ & Enxofre & 0,0020 \\
\hline & Silício & 0,2400 & & Silício & 0,2200 \\
\hline & Titânio & 0,0010 & & Titân nio & 0,0020 \\
\hline & Vanádio & $<0,003$ & & Vanádio & $<0,0003$ \\
\hline
\end{tabular}

A macrografia realizada nos CPs designados, conforme Tabela 2, torna possível identificar as regiões existentes, podendo avaliar a extensão da ZTA e sua proporcionalidade em relação às zonas fundidas. A Figura 6 ilustra duas das macrografias registradas neste trabalho.

A análise macrográfica realizada nos CPs confeccionados com ER 70S-3 apresentam uma ZTA bem definida, tendo uma raiz mais homogênea associada à menor velocidade de resfriamento devido aos passes de solda depositados acima da mesma. Já os CPs confeccionados com ER 80S-Ni2 apresentam uma zona termicamente afetada e camadas provenientes do processo de soldagem menos definida que nos CPs obtidos com o consumível ER 70S-3, provavelmente devido à reação diferenciada do tipo de material de solda. Estes últimos também possuem uma raiz mais homogênea.
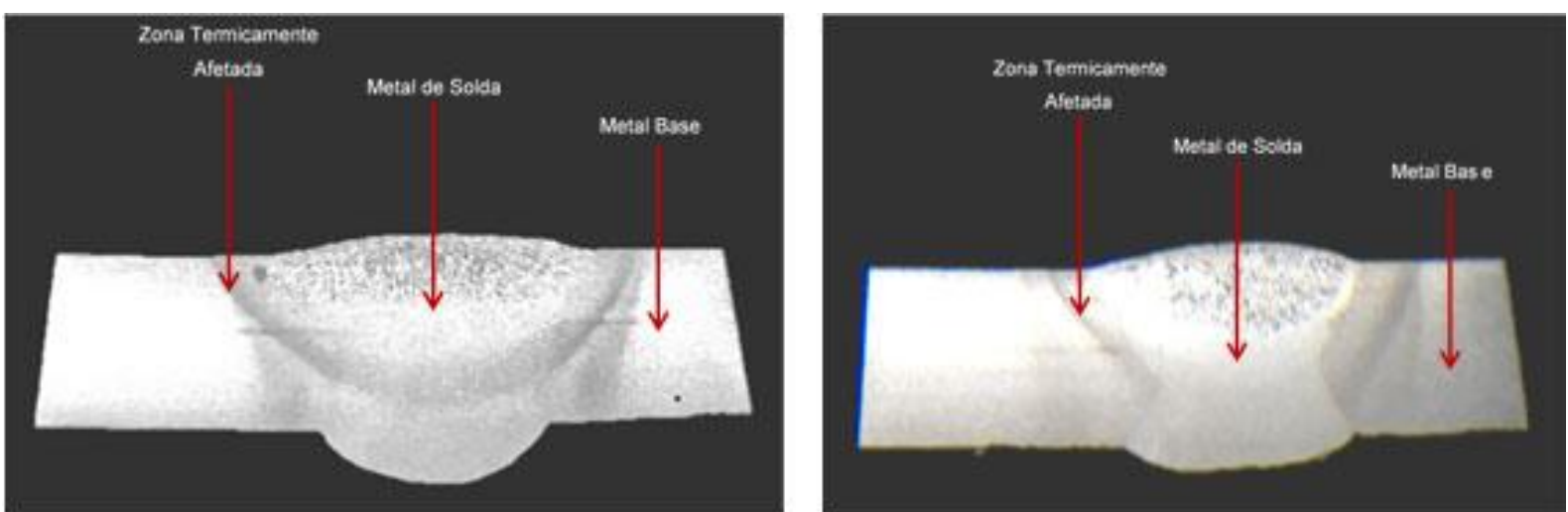

Figura 6. Macrografia do CP soldado com consumível ER 70S-3 (esquerda) e ER 80S-Ni2 (direita).

Na micrografia, Figura 7 , pode se analisar no material de base utilizado para a confecção dos CPs a presença dos microconstituintes, ferrita e perlita, composição 
normal para um aço carbono estrutural comum. Verificando na configuração da perlita um grande bandeamento para o tubo, característica comum ao processo de fabricação de tubos sem costura. Já a chapa possui características semelhantes ao metal de base do tubo, exceto que a perlita apresenta menor bandeamento.
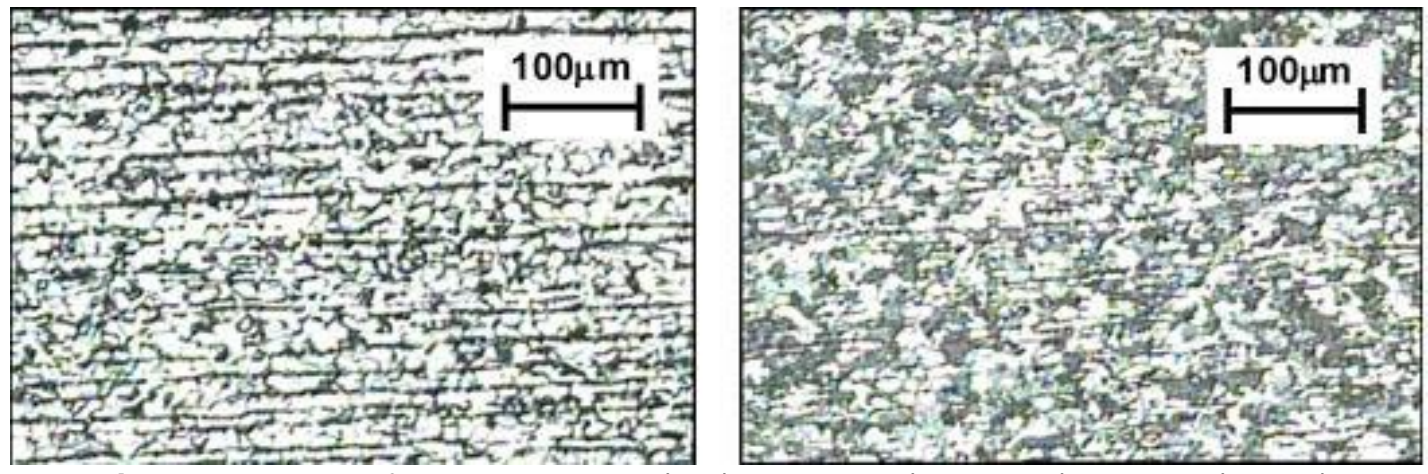

Figura 7. Micrografia do metal base (MB) dos tubos (esquerda) e chapa (direita).

A ZTA em diversas localidades, com ampliações de 50x e 100x, apresentou em todos os casos uma microestrutura normal, caracterizado por uma estrutura fina de perlita e ferrita, devido ao aporte térmico de soldagem, sem a formação de martensita.

O MS na região do acabamento, apresentou os microconstituintes perlita com ferrita agulhada, devido à alta taxa de resfriamento na camada superficial da solda, por estar em contato direto com o meio externo. O MS localizado na raiz possui como característica ferrita e perlita equiaxial, devido à baixa taxa de resfriamento desta camada. O passe de raiz, pelo efeito do aquecimento e resfriamento das camadas posteriores, tem a sua velocidade de resfriamento baixa.

Em consequência da presença de níquel nos CPs obtidos com o uso do consumível ER 80S-Ni2, criou-se uma tendência de formação de uma estrutura bifásica, que consiste na predominância de duas fases na sua microestrutura, neste caso, perlita e ferrita. A Figura 8 resume as principais características descritas.
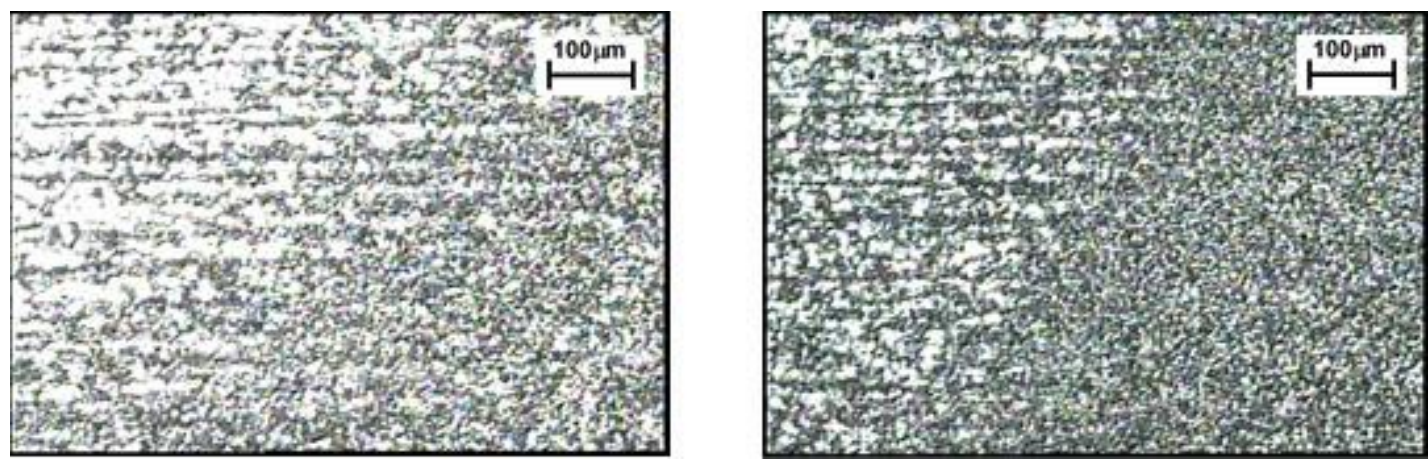

Figura 8. Micrografia do obtida entre o MB e ZTA na porção superior dos tubos empregando o consumível ER 70S-3 (esquerda) e ER 80S-Ni2 (direita).

Após a imersão dos CP's na cuba, se tornou possível observar o surgimento de bolhas junto às peças. No decorrer do ensaio, foi possível observar alterações na coloração da solução devido à grande presença de metal solubilizado e depositado no fundo da cuba, decorrente da corrosão. Junto ao acompanhamento dos parâmetros do ensaio, se efetuou o acompanhamento fotográfico do aspecto da solução e na evolução aparente da corrosão nos CPs. Ao término do ensaio foram 
obtidos os valores de perda de massa, através da pesagem inicial e final, e assim calculada a taxa de corrosão de cada CP conforme a NACE RP 0775:2005 [4]:

sendo:

$$
\mathrm{T}_{\mathrm{c}}=\frac{K \cdot W}{A \cdot T \cdot D}
$$

Tc a taxa de corrosão, (mm/ano)

$\mathrm{K}$ uma constante, adimensional

T o tempo de exposição, (h)

A a área $\left(\mathrm{cm}^{2}\right)$

W a perda de massa $(\mathrm{g})$

D a densidade em $\mathrm{g} / \mathrm{cm}^{3}$

Após a obtenção dos dados de perda de massa, com a constante $\mathrm{K}$ obtida no item

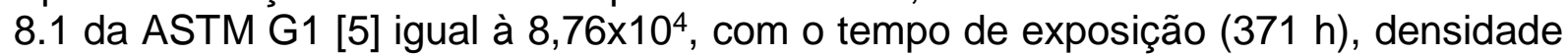
do material $\left(7,86 \mathrm{~g} / \mathrm{cm}^{3}\right)$ e com as áreas de exposição de 133,4 e $110 \mathrm{~cm}^{2}$ para tubos e chapas, respectivamente, foi possível calcular as taxas de corrosão para cada CP utilizando a Equação 1. Os resultados estão apresentados na Tabela 4.

Tabela 4. Taxas de corrosão das amostras de chapas e de tubos empregados neste trabalho. Os CPs de 1 a 3 foram obtidos com consumível ER 70S-3 e os CPs de 4 a 6 com o ER 80S-Ni2.

CHAPA

\begin{tabular}{l|c|c|c}
\hline $\mathbf{C P}$ & $\mathbf{A}$ & $\mathbf{W}$ & TC \\
\hline $\mathbf{0 1}$ & $110,0 \mathrm{~cm}^{2}$ & $20,870 \mathrm{~g}$ & $5,70 \mathrm{~mm} /$ ano \\
\hline $\mathbf{0 2}$ & $110,0 \mathrm{~cm}^{2}$ & $19,545 \mathrm{~g}$ & $5,34 \mathrm{~mm} /$ ano \\
\hline $\mathbf{0 3}$ & $110,0 \mathrm{~cm}^{2}$ & $16,006 \mathrm{~g}$ & $4,37 \mathrm{~mm} /$ ano \\
\hline $\mathbf{0 4}$ & $110,0 \mathrm{~cm}^{2}$ & $21,928 \mathrm{~g}$ & $5,99 \mathrm{~mm} /$ ano \\
\hline $\mathbf{0 5}$ & $110,0 \mathrm{~cm}^{2}$ & $20,416 \mathrm{~g}$ & $5,58 \mathrm{~mm} /$ ano \\
\hline $\mathbf{0 6}$ & $110,0 \mathrm{~cm}^{2}$ & $22,621 \mathrm{~g}$ & $6,18 \mathrm{~mm} /$ ano \\
\hline
\end{tabular}

TUBO

\begin{tabular}{l|c|c|c}
\hline $\mathbf{C P}$ & $\mathbf{A}$ & $\mathbf{W}$ & TC \\
\hline $\mathbf{0 1}$ & $133,4 \mathrm{~cm}^{2}$ & $121,819 \mathrm{~g}$ & $27,43 \mathrm{~mm} / \mathrm{ano}$ \\
\hline $\mathbf{0 2}$ & $133,4 \mathrm{~cm}^{2}$ & $109,045 \mathrm{~g}$ & $24,56 \mathrm{~mm} / \mathrm{ano}$ \\
\hline $\mathbf{0 3}$ & $133,4 \mathrm{~cm}^{2}$ & $124,344 \mathrm{~g}$ & $28,00 \mathrm{~mm} / \mathrm{ano}$ \\
\hline $\mathbf{0 4}$ & $133,4 \mathrm{~cm}^{2}$ & $115,635 \mathrm{~g}$ & $26,04 \mathrm{~mm} /$ ano \\
\hline $\mathbf{0 5}$ & $133,4 \mathrm{~cm}^{2}$ & $121,643 \mathrm{~g}$ & $27,40 \mathrm{~mm} /$ ano \\
\hline $\mathbf{0 6}$ & $133,4 \mathrm{~cm}^{2}$ & $120,227 \mathrm{~g}$ & $27,08 \mathrm{~mm} / \mathrm{ano}$ \\
\hline
\end{tabular}

A diferença obtida na taxa de corrosão entre os tubos e as chapas está relacionada ao fato que os tubos tiveram somente corrosão uniforme e as chapas apresentaram além da corrosão uniforme, corrosão por pites, conforme ilustrado na Figura 9. A taxa de corrosão determinada por perda de massa mede apenas a corrosão determinada por perda de massa mede apenas a corrosão uniforme. Portanto, para se avaliar a corrosão das chapas é preciso calcular a taxa de pite que mede a corrosão devido aos pites e adotar como a taxa de corrosão das chapas a maior das duas. A NACE RP0775:2005 [4] recomenda o emprego da equação 2 para cálculo da taxa de pite (TP).

sendo:

$$
\mathrm{TP}=\frac{P P M P}{T} .365
$$

TP: taxa de pite, $(\mathrm{mm} / \mathrm{a})$

PPMP: Profundidade do Pite Mais Profundo, $(\mathrm{mm})$

$\mathbf{T}$ : tempo de exposição, (dias)

A ocorrência de pites na chapa está associada a quantidade de enxofre na composição química da chapa, apresentada na Tabela 3, que foi cerca de 5 vezes maior que a quantidade de enxofre na composição química dos tubos. Essa 
interferência é descrita por Fontana e Greene [6]. Como não foram medidas grandes diferenças nas taxas de corrosão, após a correção pela taxa por pite, a avaliação da influência da soldagem foi efetuada de maneira qualitativa, através da inspeção visual.

Visualmente os CPs confeccionados com o ER 80S-Ni2 apresentam pontos de corrosão mais acentuada se comparado aos soldados com o ER 70S-3. Nestes, destacam-se as zonas de ligação entre a material base e de solda, na ZTA, onde se formaram canais de corrosão visivelmente mais afetada que nas demais regiões, evidenciando a formação de pilha galvânica. Este cenário está ilustrado na Figura 9.
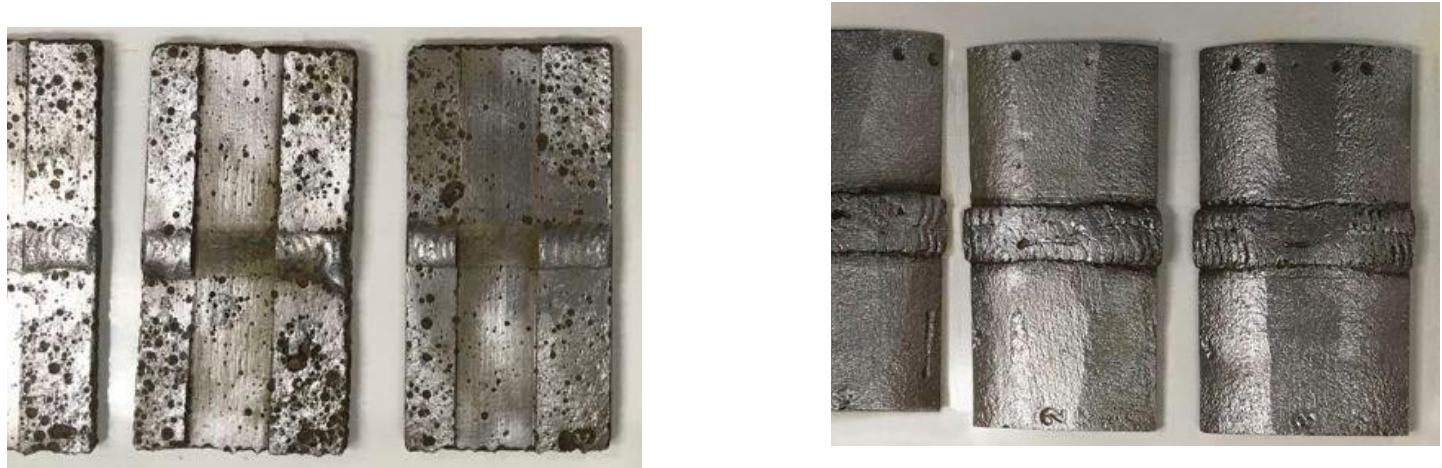

CPs soldados com consumível ER 70S-3 (similar ao metal base)
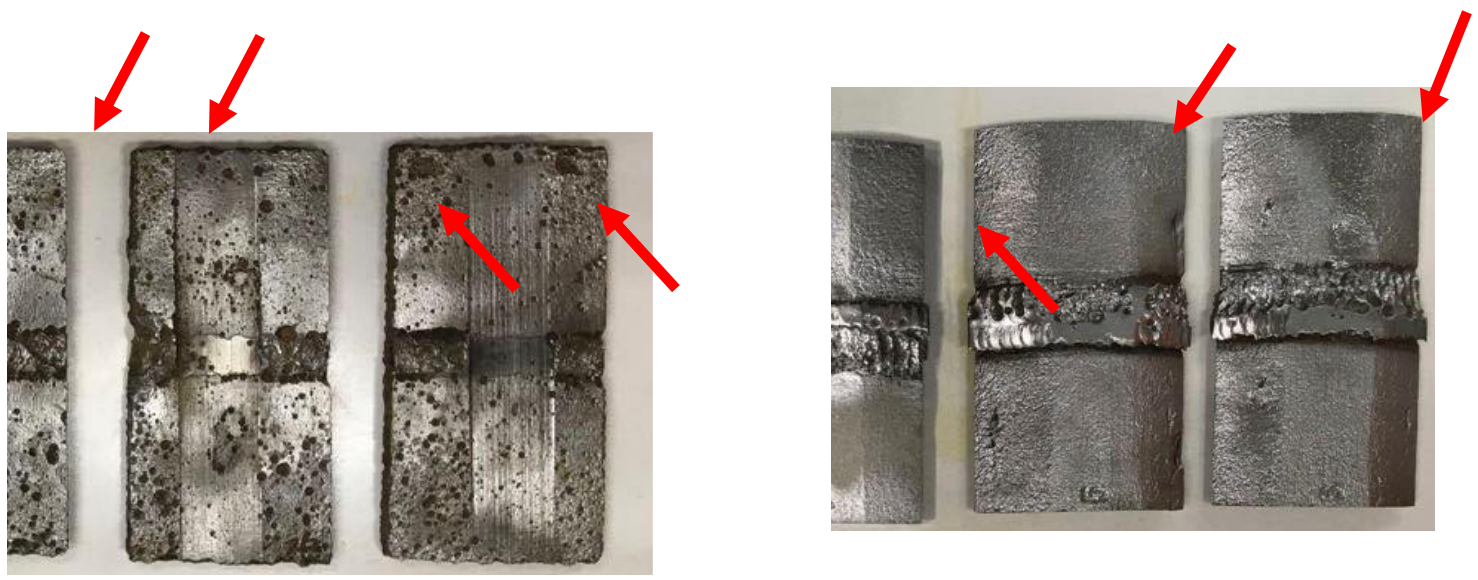

CPs soldados com consumível ER 80S-Ni2 (dissimilar ao metal base)

Figura 9. Aspecto dos CPs após ensaios de corrosão acelerada soldados com consumíveis similares e dissimilares ao metal base: amostras de chapa (esquerda) e tubo (direita). 
A corrosão assimétrica apresentada nos CPs de tubos soldados com o consumível ER 80S-Ni2, dissimilar ao metal base, originou-se devido aos mesmos possuírem uma diluição diferenciada do material de base em um dos lados do cordão de solda. Esta diluição diferenciada levou aos mesmos a serem mais suscetível ao processo de corrosão galvânica mais localizada em um dos lados da junta, como mostrado nas três fotos na parte inferior direita da Figura 9.

Os resultados obtidos para a medição de rugosidade no MB e MS dos CPs soldados com o consumível ER 80S-Ni2 apresentaram expressivamente uma evolução melhor que os soldados com o ER 70S-3. Porém os CPs soldados com o consumível ER 80S-Ni2 criou regiões profundamente afetadas que impossibilitaram a medição da rugosidade na ZTA, forçando a escolha de locais não representativos ao aspecto superficial da região. Os resultados obtidos das diferenças das rugosidades antes e após o teste de corrosão acelerada nos CPs analisados estão contidos na Tabela 5. Com os resultados obtidos no ensaio de tração, foi possível gerar gráficos que demonstram as zonas elástica e plástica dos CPs. Foram realizados dois ensaios para cada situação, resultando em quatro gráficos para juntas soldadas com ER 70S-3 e quatro gráficos para os soldados com o ER 80S-Ni2, igualmente antes e após o ensaio de corrosão acelerada, conforme descrito na Tabela 2.

Devido à presença do elemento níquel, os CPs soldados com o consumível ER 80S$\mathrm{Ni} 2$ apresentaram uma transição elástico-plástica, região do escoamento, menos acentuado e uma maior resistência do material, tanto para chapa quanto para tubo

Tabela 5. Resultados Diferença entre a média das rugosidades antes e após os ensaios de corrosão acelerada nos materiais analisados neste trabalho.

\begin{tabular}{c|c|c|c|c|c|c|c|c}
\hline \multirow{2}{*}{$\begin{array}{c}\text { Tipo de } \\
\text { Consumivel }\end{array}$} & \multicolumn{2}{|c|}{ MB } & \multicolumn{2}{c|}{ ZTA } & \multicolumn{2}{c|}{ MS } & \multicolumn{2}{c}{ Média } \\
\cline { 2 - 9 } & Tubo & Chapa & Tubo & Chapa & Tubo & Chapa & Tubo & Chapa \\
\hline ER 70S-3 & 5,45 & 0,42 & 4,83 & 1,87 & 5,52 & 7,61 & 5,27 & 3,30 \\
\hline ER 80S-Ni2 & 4,05 & 1,38 & 3,32 & 2,44 & $-0,30$ & $-0,44$ & 2,36 & 1,13 \\
\hline
\end{tabular}

* Valores obtidos em $\mu \mathrm{m}$

O ensaio de corrosão acelerada alterou o comportamento mecânico dos materiais, devido à presença dos produtos de corrosão, que se manifestam em forma de imperfeições superficiais como porosidades, trincas, etc. Como o material deixa de ser homogêneo, a deformação do mesmo passa a ser inconstante perdendo a sua ductilidade e tendo um escoamento constante, sujeito a deformações plásticas e elásticas simultaneamente, por isso não é possível observar a transição entre estas regiões, no gráfico gerado pelo ensaio. Outra característica a ser observada é a perda de tenacidade dos materiais, associada à área inferior do gráfico devido ao processo corrosivo.

As juntas obtidas similares, obtidas com o consumível ER 70S-3, tiveram características de ruptura semelhantes aos anteriores à corrosão com exceção de apenas um CP que rompeu abruptamente devido a formação de uma trinca por hidrogênio proveniente da exposição à solução de ácido sulfúrico. Para juntas similares após o processo de corrosão, foram obtidas três curvas válidas, das quais uma cai abruptamente, e uma curva desconsiderada (devido a um problema no ensaio). Para as juntas dissimilares, obtidas com o consumível ER 80S-Ni2, das quatro curvas obtidas, duas caem de maneira abrupta, ou seja, estes CPs tendem a romperem-se mais rapidamente, o que indica um grau de concentração de tensão mais severo. 
Apesar de a corrosão alterar o comportamento mecânico de forma semelhante para as juntas similares e dissimilares, os CPs soldados com consumível ligado ao níquel (ER 80S-Ni2) apresentaram canais de corrosão, mostrados na Figura 9, onde estes atuam como concentradores de tensão, levando à intensificação de um estado triplo de tensão, causando rompimento abruto na ZTA e com fratura com caracteristicamente não linear, podendo ser observado com clareza na Figura 10.
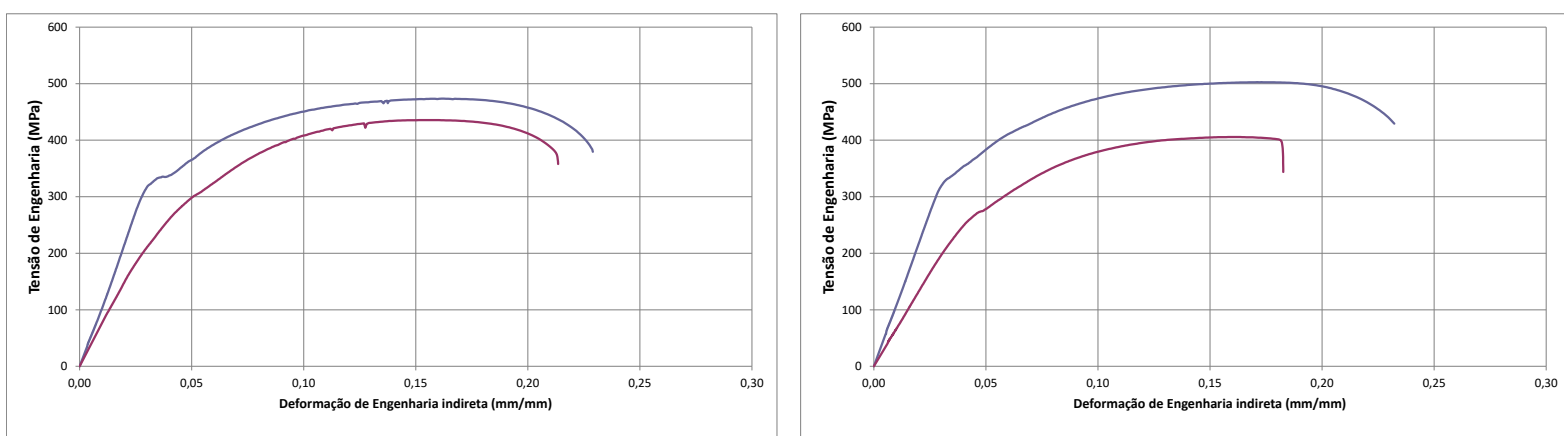

Figura 10. Gráficos tensão $\times$ deformação em CPs de tubos soldados antes e após os ensaios de corrosão acelerada: com consumível ER 70S-3 (esquerda); com consumível ER 80S-Ni3 (direita).

\section{CONCLUSÃO}

Com o intuito de analisar o diferente desempenho de juntas similares, obtidas com o consumível ER 70S-3, e dissimilares, com o consumível ER 80S-Ni3, foram utilizados métodos qualitativos e quantitativos para compreender o comportamento do processo de corrosão decorrente da aplicação de consumíveis distintos no processo de soldagem através de ensaios de tração, metalografia, perda de massa e rugosidade.

Analisando de forma quantitativa, os materiais apresentaram resultados semelhantes em algumas técnicas, especialmente em termos de taxa de corrosão, ao contrário das análises qualitativas e de algumas quantitativas que evidenciaram um comportamento distinto, especialmente em termos de análise visual, verificados pela realização de experimentos de laboratório cuidadosamente planejados que reproduziram de forma mais fiel possível às condições de serviço. A maior perda de espessura na zona de ligação das soldas dos corpos de prova com deposição da vareta ER 80S-Ni2 devido a formação de pilha galvânica, com formação de valetas estreitas e profundidade suficiente para gerar pontos de concentração de tensões.

Em relação ao comportamento mecânico, como a corrosão superficial foi notoriamente diferente, levando ao material soldado com o consumível ligado ao níquel uma maior concentração de imperfeições, faz este conjunto ter uma maior perda no seu desempenho mecânico. Os resultados dos ensaios de tração comprovam tal questão.

Assim sendo, este estudo evidencia que os materiais soldados com o consumível ER 70S-3 tiveram comportamento mecânico similar aos soldados com o ER 80S$\mathrm{Ni2}$, entretanto a resistência a corrosão das juntas similares obteve melhor desempenho associado a não formação de pilha galvânica. 


\section{Agradecimentos}

Os autores gostariam de agradecer o apoio da empresa INSPE///BRAS ${ }^{\circledR}$ no fornecimento dos consumíveis de solda, dos equipamentos e da mão de obra para a execução das juntas soldadas analisadas neste trabalho.

\section{REFERÊNCIAS}

1 GENTIL, V. Corrosão. 6. ed. Rio de Janeiro: LTC, 2011.

2 REY, A. R.; VIEIRA JUNIOR, M. A. G.; SAMPAIO, G. G.; SOUZA, L. P.; MORAIS, W. A. Análise do Desempenho de uma Junta Soldada para Tubulações de uma Plataforma Marítima. In: XIII SIMPÓSIO INTERNACIONAL DE CIÊNCIAS INTEGRADAS DA UNAERP CAMPUS GUARUJÁ, 2016, Guarujá. Anais do XIII SICI. Ribeirão Preto: UNAERP, 2016.

3 CARVALHO, N. F. D. Influência do Passe de Revenimento na Resistência à Corrosão ácida em aços de baixa liga. Dissertação de Mestrado. Universidade Santa Cecília. Santos, p. 92. 2015.

4 NACE STANDARD RP0775. Preparation, Installation, Analysis, and Interpretation of Corrosion Coupons in Oilfield Operations. [S.I.]: [s.n.], 2005

$5 \quad$ ASTM Standard G1, 2011, "Standard Practice for Preparing, Cleaning, and Evaluating Corrosion Test Specimens", ASTM International, West Conshohocken, PA, DOI: 10.1520/G0001-03R11.

6 FONTANA, M. G.; GREENE, N. D. Corrosion Engineering. 2. ed. New York: McGrawHill, v. 27, 1978. 26 p. 